\title{
Diabetic Patients and Ramadan
}

\author{
Syed Abbas Raza and Mariam Hassan \\ Shaukat Khanum Memorial Cancer Hospital and Research Centre, Lahore, Pakistan
}

\begin{abstract}
More than 50 million people with diabetes mellitus fast during Ramadan, a religious obligation for all healthy adult Muslims. Fasting leads to several physiological changes in the body and these may result in acute complications in persons with uncontrolled diabetes such as hyperglycemia, hypoglycemia, diabetic ketoacidosis, dehydration and thrombosis. Evidence from existing literature guides the physicians in their assessment of Muslim patients with diabetes who wish to fast. Assessment should include risk stratification based on existing control of diabetes and its chronic complications. In the light of this assessment medical recommendation is given which includes dose modification of oral medication and insulin, dietary advice and structured patient education.
\end{abstract}

Key Words: diabetes mellitus, Ramadan, Risk stratification

\section{INTRODUCTION}

Recent demographic projections based on current population data and related trends estimate that the global Muslim population is expected to rise from 1.6 billion in 2010 to 2.2 billion by 2030, with an average annual growth rate of $1.5 \% .^{1}$ Estimates from population-based studies show that more than 50 million people with diabetes fast during Ramadan. ${ }^{2}$ Fasting from predawn (Sahur) till sunset (Iftar) during Ramadan, a holy month of Islam is mandatory for all healthy adult Muslims. Those fasting during this month must not consume food, drinks or use any medication during the required time period of fasting. Hence, consumption of food and liquids, etc., is done at Sahur and Iftar times. However, religious exemption is available to individuals who are temporarily or permanently unable (such as the sick, the old, pregnant women or feeding mothers) to fulfil this duty.

Fasting brings about many physiological changes in the body which become especially challenging in persons with diabetes in whom prolonged gaps between meals can be a source of medical emergencies. Therefore, it is important that healthcare providers are not only aware of all the risks involved but are also aware of how to manage these risks.

We must emphasize that this feature article is a clinical guidance only and presents recent medical evidence for medical management of diabetic persons who fast during Ramadan. The recommendations made in this article are not meant as 'sanction' or countersanction on the spiritual matter of fasting. All diabetic patients who wish to fast must do so in light of appropriate religious advice and in consultation with their healthcare provider.

ISSN 0857-1074

Printed in the Philippines

Copyright $(0) 2013$ by the JAFES

Received October 19, 2012. Accepted April 23, 2013.

\section{Major Changes in Body Physiology during Fasting}

There is paucity of controlled studies on Ramadan and diabetes with most of the available evidence being the result of epidemiological/survey-based studies. Also, most of the available evidence is not comparable due to variations and deficiencies in study designs such as lack of non-fasting controls, variations in blood sampling times, differences in lifestyles and nutritional habits, lack of information on fasting duration as well as the timing during Ramadan. ${ }^{3}$ The discrepancy of results between various studies, although partly explained in terms of protocol differences, creates ambiguity in clinical decision making.

Seasonal variation in the occurrence of Ramadan is also one of the reasons for discrepancy in results of various studies. Ramadan is a lunar month and the season during which Ramadan falls changes over a period of time. Currently, Ramadan falls in summer in the northern hemisphere and will remain so for next few years. This would mean that the length of fast in non-equatorial countries would increase to about 16-20 hours. Longer fasting periods also increase the chances of developing complications for persons with diabetes who fast. ${ }^{4}$

\section{Effect on blood glucose levels}

In normal individuals, the alterations in blood glucose levels during Ramadan are within the 'normal physiological range.' Variations in blood glucose in fasting persons with diabetes depends upon the length of fasting hours, medicine intake, changes in physical activity and caloric intake at Sahur and Iftar, the two usual times for consumption of food during Ramadan. ${ }^{5}$

Corresponding author: Syed Abbas Raza, MD

Consultant Endocrinologist

Shaukat Khanum Memorial Cancer Hospital and Research Centre (SKMCH \& RC)

7-A, Block R-3, M.A. Johar Town, Township, Lahore, PO Box 13014

Tel. No.: +92-42-35905000 (Ext. 4286)

Fax No.: +92-42-35945209

E-mail: sabbasraza@hotmail.com 
A significantly increased risk of severe hypoglycemia and of severe hyperglycemia in fasting persons with type 2 diabetes was seen during Ramadan in the EPIDIAR (Epidemiology of Diabetes and Ramadan) study. ${ }^{6}$ Results from other observational studies show variance in the risk of hypoglycemia in fasting persons with diabetes. ${ }^{4}$

\section{Effect on body weight}

Fasting during the daytime is compensated for by the body physiology and, thus, normal body weight is maintained during Ramadan. However, the changes in diet patterns (greater intake of sugary fluids, high fat and carbohydrate rich diet) during non-fasting hours pose a risk for weight gain. ${ }^{7}$ To avoid fluctuations in weight, diabetic patients should spread the caloric load per day over the non-fasting period.

\section{Changes in Biochemical Parameters}

\section{HbA1c, plasma insulin and insulin resistance}

Benaji et al, indicate in their literature review (2006) that $\mathrm{HbA1c}$ values do not change during Ramadan, in fact in some cases, even a decrease has been demonstrated during this month. Fasting plasma insulin levels do not change either. However, recent reports indicate decreased levels in men, most of these being later in the day. A significant decrease in insulin resistance was seen only in male patients with diabetes who fasted during Ramadan. ${ }^{3}$

\section{Effect on lipid metabolism}

No significant change in total cholesterol, LDL- and HDLcholesterol levels were seen in several studies. ${ }^{8-10}$ However, some reports point to a decrease in triglycerides ${ }^{11,12}$ and an increase in total cholesterol during Ramadan fasting. ${ }^{13}$

\section{Micro and macroangiopatic complications}

The prevention and treatment of macro- and microangiopathic complications is based on several parameters such as blood pressure, $\mathrm{HbA1c}$, lipid profile, smoking, BMI and physical activity. Benaji et al., report a comparison of the biochemical changes during Ramadan to recommended values for these risk factors. However, it is difficult to draw conclusions since there was a lack of prior control for these risk factors as well as lack of information on angiopathic complications before Ramadan. ${ }^{3}$

\section{Other biochemical parameters}

Values for serum creatinine, blood urea nitrogen, and uric acid, serum albumin and globulin and liver transaminases did not show significant changes in persons with well controlled diabetes who fasted during Ramadan. ${ }^{5}$

\section{Common Complications of Diabetes during Ramadan}

The major acute complications seen in persons with diabetes during fasting in Ramadan include

- Hypoglycemia

- Hyperglycemia
- Diabetic ketoacidosis

- Dehydration and Thrombosis

\section{Hypoglycemia}

Fasting is attributed to an increased risk of hypoglycemia especially in old patients ( $>60$ years) and those with good glycemic control $(<8 \%)^{14}$ The EPIDIAR study showed an increased risk (7.5 times in type 2 diabetes) of severe hypoglycemia (requiring hospitalization) in fasting persons with type 2 diabetes. The propensity for severe hypoglycemia increased with changes in doses of oral agents or insulin and major shifts in physical activity. ${ }^{6}$ Evidence for risk of fatal hypoglycemia in type 2 diabetic patients who fast is lacking. The risk is also lower in persons with type 2 diabetes compared with type 1 diabetes, especially for those on oral agents. ${ }^{15}$

\section{Hyperglycemia}

As with hypoglycemia, a major change in medication dosage (more specifically a reduction or stoppage) ${ }^{15}$ or diet (higher sugar intake during non-fasting times) increased the risk for hyperglycemia by several fold. ${ }^{6}$ Current data, however, do not provide information on the effect of repeated short term acute increases in blood glucose levels during Ramadan on the development of chronic complications of diabetes. ${ }^{15}$

\section{Diabetic ketoacidosis (DKA)}

Studies have not indicated an increased risk of DKA during Ramadan. ${ }^{16-18}$ However, in theory, the chances of developing DKA are considered to be higher due to hypoinsulinemia and hyperglucagonemia and ketone body formation which result from fasting. ${ }^{19}$ Hence, the following patients are considered to be at an increased risk of DKA: ${ }^{15}$

- $\quad$ Patients with type 1 diabetes with impaired glycemic control pre-Ramadan, especially those whose insulin dosage is reduced drastically during this month.

- Patients who develop dehydration (leads to increased blood viscosity and a hypercoagulable state)

- Patients with micro- or macrovascular complications or other co-morbid conditions

- Acute infection, as insulin dose may become inadequate to fulfill the body's stress requirements

\section{Dehydration and thrombosis}

Prolonged decreased fluid intake can lead to dehydration. This is especially applicable to countries where climate is hot and humid and when Ramadan falls in the summer, which is likely to be the case for the next decade. In addition, hyperglycemia can also contribute to osmotic diuresis and eventually water and electrolyte loss. Higher blood viscosity due to dehydration can lead to increased risk of thrombosis and stroke. ${ }^{2}$

\section{Pre-Ramadan Assessment of Persons with Diabetes}

The EPIDIAR study conducted in 13 Muslim countries on more than 12,000 persons with diabetes who fasted during 
Ramadan showed a high rate of acute complications. ${ }^{6}$ However, few other studies with smaller number of patients, show that the frequency of complications may not be significantly increased. ${ }^{20,2}$ All diabetic patients need assessment of suitability for fasting at least one to two months before Ramadan (summarized in Table 1). ${ }^{3}$

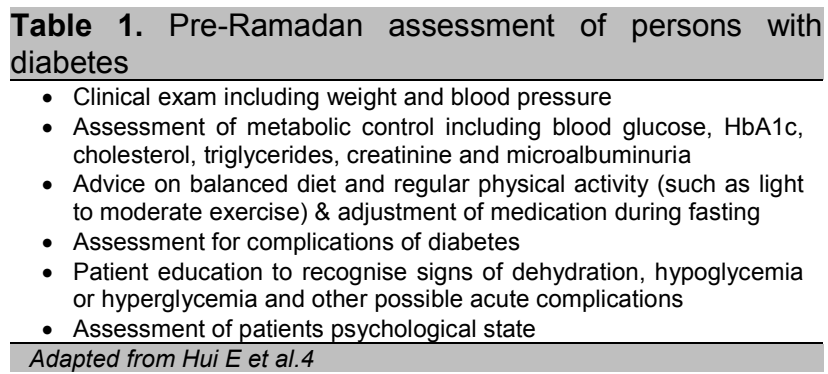

\section{Risk Stratification for Assessment}

Based on expert opinion the risk stratification for assessment of medical suitability in persons with diabetes who wish to fast during Ramadan is shown in Table $2 .^{2}$

Patients in the high risk categories have a very high likelihood of developing acute complications such as severe hypoglycemia, hyperglycemia, DKA, etc., and are, hence, advised to avoid fasting by healthcare providers. Patients at moderate risk can manage to fast provided they reduce their risk by making changes to their diabetes treatment in consultation with a healthcare professional. Patients in the low risk category can manage fasting without any additional risk of complications. ${ }^{4}$

It must be re-emphasized that fasting represents an important personal decision that is made in the light of religious guidelines and relevant exemptions and after consideration of the associated risks in consultation with healthcare providers.

\section{Ramadan Focused Diabetes Education}

Results from the Ramadan Prospective Diabetes Study, although limited due to lack of a control group, strongly point towards the positive impact of adequate glucose monitoring, adjustment of medication as well as patient education. $^{22,23}$
The following summarizes the four key areas of counselling and education for persons with diabetes who wish to fast during Ramadan: 3,24,25,26

1. Dietary advice should emphasize a balanced diet and should include

- Slow energy release foods which should be consumed at Sahur and Iftar time meals

- Minimal intake of foods with high fat content and monounsaturated fats

- Increased use of foods with high fiber content

2. Exercise

- Patients should maintain their routine physical activity

- Persons with type 2 diabetes can do light and moderate exercise safely during fasting. Tarawaih (series of post-sunset prayers) should be considered a part of exercise

- Risk of hypoglycemia may increase with more intense exercise regimens and, hence, should be avoided, especially in patients who are using sulfonylureas or insulin

3. Blood glucose monitoring

- Frequent blood glucose monitoring is essential and is not considered a break of the fast

- Fasting persons with diabetes should make prior arrangements for blood glucose monitoring

- Blood glucose should be checked especially - When symptoms of hypoglycemia occur - The patient is unwell (e.g., has a fever)

4. Recognizing and managing complications

- Patients should be educated to recognize the symptoms of dehydration, hypoglycemia and hyperglycemia and also about the home measures to remedy these.

- Fasting should be stopped in cases of complications or any acute illness

\section{Management of Medication during Ramadan}

\section{Oral Hypoglycemic Agents}

\section{Biguanides}

Severe hypoglycemia (requiring hospitalization) is not reported with metformin when it is used as monotherapy.

Table 2. Risk stratification for persons with diabetes who wish to fast during Ramadan

\begin{tabular}{|c|c|c|c|}
\hline Very High Risk & High Risk & Moderate Risk & Low Risk \\
\hline $\begin{array}{l}\text { - Severe hypoglycemia (requiring } \\
\text { hospitalization) or diabetic } \\
\text { ketoacidosis within the } 3 \text { months } \\
\text { before Ramadan } \\
\text { - Uncontrolled diabetes } \\
\text { - Repeated hypoglycemia especially } \\
\text { when associated with unawareness } \\
\text { - Patients requiring chronic dialysis } \\
\text { - Type } 1 \text { diabetes especially when } \\
\text { - } \text { uncontrolled } \\
\text { - } \text { Daily routine involving intense } \\
\text { - physical labour } \\
\text { - Pregnant women }\end{array}$ & $\begin{array}{l}\text { - Blood glucose in the range of } \\
150-300 \mathrm{mg} / \mathrm{dl} \text { or } \mathrm{HbA} 1 \mathrm{c} \\
\text { between } 7.5-9.0 \%) \\
\text { - Patients on insulin or } \\
\text { sulfonylureas who live alone } \\
\text { - Chronic complications such as } \\
\text { renal, macro vascular, etc. } \\
\text { - Old patients with co- morbidities } \\
\text { - Patients on drugs that affect } \\
\text { mental alertness }\end{array}$ & $\begin{array}{l}\text { - Well-controlled diabetes on } \\
\text { short-acting insulin } \\
\text { secretagogues }\end{array}$ & $\begin{array}{l}\text { - Well-controlled diabetes } \\
\text { treated with lifestyle therapy, } \\
\text { metformin, acarbose, and/or } \\
\text { incretins with no co-morbid } \\
\text { conditions }\end{array}$ \\
\hline
\end{tabular}


It is, however, recommended for patients taking metformin more than once a day to use $1 / 3 \mathrm{rd}$ of the total daily dose with meals at Sahur and the rest at Iftar time. ${ }^{27}$

\section{Sulfonylureas}

This group is used with caution in fasting because of its inherent risk of hypoglycemia. Second generation sulfonylureas such as gliclazide, glimepiride and glipizide are preferable to chlorpropamide, glyburide (glibenclamide) because of the increased risk of prolonged and unpredictable hypoglycemia with the latter drugs. ${ }^{28,29}$ These agents are likely to continue to be used because of their low cost. However, the use of these agents should be individualized and used with caution during Ramadan.

\section{Alpha glucosidase inhibitors}

Evidence for this drug's use and its effects during fasting is lacking. However, results from a recent randomized study showed a low risk of hypoglycemia with this class of drugs. ${ }^{30}$ Use of routine dose with meals can be continued during Ramadan.

\section{Short-acting insulin secretagogues}

Repaglinide and nateglinide have a short duration of action and, hence, can be taken at the two meals during Ramadan, the lowest risk of hypoglycemia being with nateglinide, having shortest duration of action amongst the secretagogues. Results from a randomized trial show that repaglinide was associated with fewer hypoglycemia events compared to glibenclamide., ${ }^{2,4}$

\section{Incretin-based therapy}

Although evidence for use of this group of drugs during fasting is lacking, incretin-based therapy, including GLP-1 agonists (exenatide and liraglutide) and DPP- 4 inhibitors (alogliptin, saxagliptin, sitagliptin, and vildagliptin) are considered low risk for hypoglycemia, but these drugs may increase hypoglycemia rates when combined with other therapies such as sulfonylureas, glinides and insulin. ${ }^{31}$

\section{Thiazolidinediones (TZDs)}

This group of drugs is not considered to pose an increased risk of hypoglycemia. However, the risk may increase in combination with other drugs during fasting. Recent safety concerns for this group such as cardiovascular safety of rosiglitazone and carcinogenic potential of pioglitazone have resulted in a more cautious use of this group..$^{27}$ Recent guideline documents have proposed a continuation of the usual dose during Ramadan in persons who are well controlled on TZDs alone or in combination with other oral agents. ${ }^{32}$

\section{Use of Insulin during Ramadan}

\section{Type 1 Diabetes}

Persons with type 1 diabetes with uncontrolled glycemic levels, on frequent doses of insulin and who experience hypoglycemia unawareness are considered medically unfit for fasting. Persons with well controlled type 1 diabetes can fast safely using basal-bolus insulin regimens. NPH or insulin analogues for basal doses and regular insulin, lispro or aspart for bolus have shown adequate efficacy and safety. Insulin pumps may be used effectively in educated persons with type 1 diabetes under careful medical guidance. ${ }^{33}$

\section{Type 2 Diabetes:}

Persons with well controlled diabetes without complications who are being managed by insulin alone or in combination with oral drugs may fast during Ramadan. A change in insulin dosage and/or regimen may be required prior to Ramadan to reduce risk of hypoglycemia. A combination of basal long acting insulin at Iftar times and short acting insulin at predawn meal is suggested for most patients. ${ }^{33}$ Short acting analogs are preferred to short acting insulin at Sahur meal since it is associated with lower incidence of hypoglycemia and lesser post meal blood glucose variations. ${ }^{34}$ Diabetic patients with good glycemic control taking twice daily insulin should reduce the dose by $30 \%$ at Sahur meal.

\section{CONCLUSION}

We face an enormous burden of diabetes in the Muslim world, but our understanding of managing diabetes during the month of Ramadan/fasting is still far from perfect. Physicians are sometimes reluctant to give advice to patients due to this quagmire. Although few recent large scale studies, including randomized trials, have been conducted in Muslim patients with diabetes, there is need for more well-designed research with appropriate controls. With newer medications, it is possible to optimize the care of these patients through prior risk stratification, tailored therapy and adequate structured counseling of individual patients.

\section{Acknowledgements}

We thank Dr. Mohammad Ahmad for his help in formatting and reviewing the article.

\section{References}

1. Brian JG, Mehtab SK. The Future Global Muslim Population. Projections for 2010-2030. [Internet] (C2011. Washington, DC, Pew Research Center. Available from: The Future of the Global Muslim Population - Pew Forum on Religion \& Public Life. Accessed October 9, 2012.

2. Al-Arouj M, Assaad-Khalil S, Buse J, et al. Recommendations for management of diabetes during Ramadan. Update 2010. Diabetes Care 2010;33:1895-902.

3. Benaji B, Mounib N, Roky R, et al. Diabetes and Ramadan: Review of the literature. Diabetes Res Clin Pract 2006; 73(2):117-25.

4. Hui E, Bravis V, Hassanein M, et al. Management of people with diabetes wanting to fast during Ramadan. BMJ 2010; 340:3053.

5. Jaleel MA, Raza SA, Fathima FN, Jaleel BNF. Ramadan and diabetes: As-Saum (The fasting). Indian Journal of Endocrinology and Metabolism. October-December, 2011; 15(4).

6. Salti I, Be'nard E, Detournay B, et al. Results of the Epidemiology of Diabetes and Ramadan 1422/2001 (EPIDIAR) study. Diabetes Care 2004; 27:2306-11.

7. Rashed H. The fast of Ramadan: No problem for the well; the sick should avoid fasting, BMJ 1992; 304:521-522. 
8. Khatib FA, Shafagoj YA. Metabolic alterations as a result of Ramadan fasting in non-insulin-dependent diabetes mellitus patients in relation to food intake, Saudi Med J 2004;25:1858-1863.

9. Nagati, K.; Kammoun, H.; Abid, A.; Blouza, S.; Jamoussi, H.; Atallah, M.et al. Diabetes and fasting during Ramadan: A multicentric Tunisian study. Médecine et Nutrition 2000 ;36 (2):90-95.

10. Sadr S, Afshar M, Sarboluki S. Effect of fasting on glucose, lipids, body weight and blood pressure among non-Insulin dependent diabetes mellitus. KAUMS Journal (FEYZ). 1998; 2 (2) :71-76

11. Sari R, Balci MK, Akbas SH, Avci B, The effects of diet, sulfonylurea and repaglinide therapy on clinical and metabolic parameters in type 2 diabetic patients during Ramadan, Endocr Res 2004;30(2):169-177.

12. Athar S, Habib M. Management of stable typical 2 diabetes mellitus (NIDDM) during Islamic fasting in Ramadan, in: The First International Congress on Health and Ramadan Casablanca, Morocco, 1994:203-212.

13. Yarahmadi SH, Larijani B, Bastanhagh $\mathrm{MH}$ et al., Metabolic and clinical effects of Ramadan fasting in patients with type II diabetes, JCPSP 2003;13:329-332.

14. Loke SC, Rahim KF, Kanesvaran R, Wong TW. A prospective cohort study on the effect of various risk factors on hypoglycemia in diabetes who fast during Ramadan. Med J Malaysia 2010; 65:3-6.

15. Ahmad J, Pathan F, Jaleel MA. Diabetic emergencies including hypoglycemia during Ramadan. IJEM 2012; 16(4):512-515.

16. Kadiki OA, Moawad SE, Khan ZA, Reddy MR, Marzoung AA. Diabetes mellitus and Ramadan. Garyounis Med J 1989; 12:32-4.

17. Azad K, Mohsin F, Zargar AH et al. Fasting guidelines for diabetic children and adolescents. Indian J Endocrinol Metab 2012; 16(4):516-8.

18. Rafik E, Mohammad E, Hanan E. Incidence of Diabetic Ketoacidosis during Ramadan Fasting in Benghazi-Libya. Oman Med J 2009; 24:99-102.

19. Al-Arouj M, Bouguerra R, Buse J et al. Recommendations for the management of diabetes during Ramadan. Diabetes Care 2005; 28:2305-11.

20. Uysal AR, Erdog an MF, Sahin G, Kamel N, Erdog an G. Clinical and metabolic effects of fasting in 41 type 2 diabetic patients during Ramadan (Letter). Diabetes Care 1998; 21:2033-2034.

21. Katibi IA, Akande AA, Bojuwoye BJ, Okesina AB. Blood sugar control among fasting Muslims with type 2 diabetes mellitus in Ilorin. Niger J Med 2001; 10:132-13.
22. Ahmedani MY, Haque MS, Basit A, Fawwad A, Alvi SFD. Ramadan Prospective Diabetes Study: The role of drug dosage and timing alteration, active glucose monitoring and patient education. Diabetic Medicine 2012; 29(6):709-715.

23. Hitman GA. Fasting, Ramadan and Diabetes. Diabetes Med 2012;29:695

24. Bravis V, Hui E, Salih S, Mehar S, Hassanein M, Devendra D. Ramadan education and awareness in diabetes programme for Muslims with type 2 diabetes who fast during Ramadan. Diabetes Med 2010; 27:327-31.

25. Mojaddidi M, Hassanein M, Malik R. Ramadan and diabetes: Evidence-based guidelines. Prescriber September 2006; 38-41.

26. Hui, E. and Devendra, D. Diabetes and fasting during Ramadan. Diabetes Metab. Res. Rev., 2010;26:606-610.

27. Bashir MI, Pathan F, Raza SA et al. Role of oral hypoglycemic agents in the management of type 2 diabetes mellitus during Ramadan. Indian Journal of Endocrinology and Metabolism. July-August, 2012; 16(4).

28. Schernthaner G, Grimaldi A, Di Mario U et al. GUIDE study: Doubleblind comparison of once-daily gliclazide MR and glimepiride in type 2 diabetic patients. Eur J Clin Invest 2004; 34:535-542.

29. Rendell M. The role of sulphonylureas in the management of type 2 diabetes mellitus. Drugs 2004; 64:1339-58.

30. Pan C, Yang W, Barona JP et al. 17 Comparison of vildagliptin and acarbose monotherapy in patients with type 2 diabetes: a 24-week, double-blind, randomized trial. Diabetes Med 2008; 25:435-41.

31. Drucker DJ, Sherman SI, Gorelick FS, Bergenstal RM, Sherwin RS Buse JB. Incretin-based therapies for the treatment of type 2 diabetes: Evaluation of the risks and benefits. Diabetes Care 2010; 33:428-433.

32. Al-Arouj M, Bouguerra R, Buse J et al. American Diabetes Association recommendations for management of diabetes during Ramadan. Diabetes Care 2005;28:2305-11.

33. Pathan F, Sahay RK, Zargar AH et al. South Asian Consensus Guideline: Use of insulin in diabetes during Ramadan. Indian Journal of Endocrinology and Metabolism. July-August 2012; 16(4).

34. Mattoo V, Milicevic Z, Malone JK, Ramadan Study Group. A comparison of insulin lispro Mix25 and human insulin 30/70 in the treatment of type 2 diabetes during Ramadan. Diabetes Res Clin Pract 2003;59:137-143.

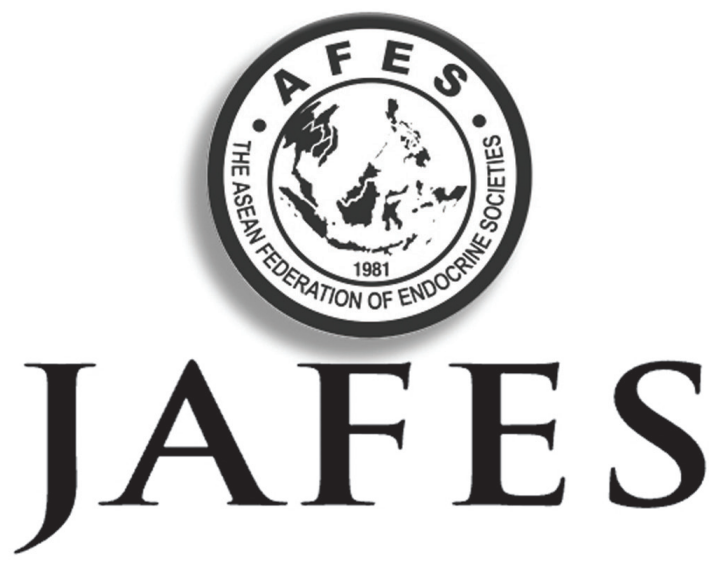

Send your paper to the publication pathway. Instructions to Authors at www.ASEAN-endocrinejournal.org. 